\title{
Web-Based Two-Way Electricity Monitoring System for Remote Solar Mini-Grids
}

\author{
Shaban Omary ${ }^{\text {a }}$ (Research Scholar), Anael Sam ${ }^{\text {a }}$ (Senior Lecturer) \\ ${ }^{a}$ Department of Communications Science and Engineering, Nelson Mandela African Institution of Science \\ and Technology, Arusha, Tanzania
}

Received: 09 September 2019; Accepted: 15 October 2019; Published: 08 November 2019

\begin{abstract}
Electricity usage monitoring systems play a vital role towards raising energy utilization awareness for consumers. Existing solar mini-grid infrastructure, however, lacks a user-friendly two-way platform to allow consumers to access information about electricity consumption. This paper proposes a cloud-based, two-way energy usage monitoring system that will allow both utility companies and consumers to access energy consumption data in a user-friendly way through a web platform. The system requirements were collected via questionnaires, interviews, and observations conducted at two solar mini-grids centres located at Arusha and Kilimanjaro regions in Tanzania. The system uses a Low Power Area Network (LPWAN) and the existing GPRS network to monitor electricity consumption data between smart meter units and the cloud server. Also, a virtual bill payment module and usage status feedback functionality have been integrated into the system to increase awareness of the cost-effective use of electricity and hence, achieve the sustainability of solar mini-grids. By using both white-box and black-box system testing approaches, findings show that the system will not only raise awareness among customers about the economical usage of electricity, but it can also be used by mini-grid companies as a source of data to determine current and future energy demands to minimize large investment costs.
\end{abstract}

Index Terms: Smart Meter, Internet of Things (IoT), Energy Monitoring, General Packet Radio Service (GPRS), Low Power Wide Area Network (LPWAN), Solar Mini-Grids, ATmega2560.

(C) 2019 Published by MECS Publisher. Selection and/or peer review under responsibility of the Research Association of Mode rn Education and Computer Science

\footnotetext{
* Corresponding author.

E-mail address: omarys@nm-aist.ac.tz
} 


\section{Introduction}

Recently, the global demand for electricity has risen significantly over the past decade due to climatic changes and technology advancement. Despite this fact, it is estimated that over half a billion of Sub-Saharan African (SSA) households have no access to any form of electricity [1]. Tanzania is known to have low electrification rates among the SSA countries, particularly in areas far from the national electricity grid. Recent data indicate that less than 40 percent of Tanzania Mainland households are connected to the national grid, while the remaining percentage is dependent on solar and other private sources, including diesel generators [2].

Expanding the national electrical grid to all community areas is not economically feasible due to several factors such as budget constraints, the country's large size, and the nature of settlements. [3,4]. Alternatively, independent Solar Home Systems (SHS) has been used by several remote households. These systems, however, do not seem to be able to handle large power requirements for normal domestic uses such as cooling and heating. In addition to that, these independent systems are relative expensive for a normal household family to purchase and operate a complete solar system that can meet the needs of household electricity. Realizing low connection rates, the Government of Tanzania under the Ministry of Energy has formulated several policies to encourage private companies to invest in solar mini-grids as a solution to extend power supply to communities out of immediate national grid's plans [5]. Solar mini-grids have appeared in many areas of Tanzania as a cost-effective solution to provide reliable electricity [6-8].

The main challenge facing current mini-grid solar systems is the lack of a two-way, low-cost and user-friendly electricity usage monitoring platform $[9,10]$. Monitoring systems used in these mini-grids were primarily designed to allow utility companies to have complete access and control over information about power usage, while customers have very little or no access to the same data. Nonetheless, the monitoring metering systems employed in the national grid are not feasible for the remote off-grid systems because, in addition to lack of full consumer participation, they are also relatively expensive for the resource-constrained mini-grid companies to afford. The existing systems are, therefore, not user-friendly, particularly for consumers with economic constraints who need reliable energy usage feedback to adjust their consumption behavior. Also, these systems do not provide utility companies with a complete bridge of establishing a transparent relationship with their customers by giving them access to consumption information [11].

Private companies operate most of the off-grid systems, and as these systems are usually resource-constrained, sustainable utilization of the installed solar power resources is necessary for investors to appreciate a quick return on investment. To achieve this, a user-friendly means of monitoring and managing consumer energy usage is required. A two-way energy monitoring system between the utility and consumers is a win-win situation for both parties. This platform acts as a tool for studying consumer energy usage behavior, which can be used as a source of data for planning current and future energy demands [12]. From the consumers' perspective, a user-friendly energy monitoring platform will raise consumers' energy usage awareness; eventually, they will adjust their usage behavior to meet their economic constraints. Findings indicate that consumers can reduce unnecessary energy consumption by $15 \%$ if they can have access to their energy usage information [13].

From the literature review, research on electricity usage monitoring and consumer awareness have not been fully investigated. Previous studies have focused more on automatic electricity meter reading systems, while little emphasis has been noticed on consumer energy utilization awareness [14].

For the past two decades, Sub Saharan Africa has witnessed the rapid expansion of mobile communication technologies as an alternative to fixed broadband networks. In Tanzania, this rapid expansion can be witnessed from the Tanzania Communication Regulatory Authority (TCRA) quarterly annual report, which indicates that the internet penetration rate in Tanzania has increased by $100 \%$ from the past five years [15]. The same report also indicates that GPRS network coverage exceeds $90 \%$ across the country. These statistics encourage the utilization of the ICT infrastructures that are rapidly growing to improve ways on how 
people access information regarding energy usage data.

Therefore the main objective of this study is to develop a web-based two-way electricity usage monitoring system for remote solar mini-grids as a solution towards raising consumers awareness on energy utilization. The web platform was chosen since it can reach out to all smart devices, irrespective of the operating system, and does not need hustles of custom downloading, installation, and update [16]. From the developers' perspective, all users will access the platform via a uniform environment, which simplifies development and troubleshooting. Compared to previous studies, the proposed system has put more emphasize on low-cost system design, stakeholder-derived system requirements, and sustainability of the system by utilizing the available technologies and infrastructures for system development. This study utilizes the existing GPRS network coverage to establish a communication link between a mini-grid centre and the cloud server. The study also employs qualitative and quantitative methodologies during the collection of system requirements from consumers and utility companies. Furthermore, the Rapid Application Development (RAD) model was used during system design and development. Finally, white-box and black-box techniques were employed during system testing and validation.

\section{Related Works}

In [17], a GSM-based automated meter reading system was proposed, a web portal was used to monitor customer billing information, and a processed bill was sent to consumers via SMS. However, the system lacks two-way communication features that will enable both utility and consumers to access consumption data. The web interface is used mainly for bill processing while the SMS is used for billing distribution. The system does not give the consumer an equal chance of accessing historical energy consumption record.

In [18] proposed an energy monitoring system using the Internet of Things (IoT), which measures and reports energy usage of the individual devices via the network. The system, however, requires that the present household power sockets be phased out and replaced with the proposed internet-connected power socket, which is not feasible for the majority of existing household electrical installations.

In [19], an IoT based smart energy meter based on the GSM module has been developed, which enables users to access current reading and associated costs on the web page. Also, when the user-defined usage threshold has been exceeded during regular usage, one can receive an SMS notification. By using this functionality, the user can adjust the threshold limit while the meter can also be remotely turned ON or OFF when needed. The system, however, not only that it provides less information to consumers, but also does not account for the users' requirements during the designing and development stage. The system requirements, therefore, are based on the author's opinions.

In [20], the author proposed a smart energy metering system which employs Long Range (LoRA) wireless technology for transferring electricity usage information between the consumer's meters and the remote server. Electricity usage data from the meter is transferred to the LoRA gateway via a LoRA module, which then relays data from multiple modules to the cloud server. From the cloud server, energy usage data is transmitted to the utility center for administrative purposes and consumers through a web portal. Consumers can view their consumption records and associated costs via the same portal. However, the methodology used to establish communication link between meters and the utility centre is not cost-effective particulary for developing countries. The utility company has to roll out LoRA infrastructure throughout the entire country while the existing cellular networks could be utilized to minimize operating costs.

In [21], a smart energy meter based on IoT has been proposed to monitor electricity usage at a domestic level. The Arduino based energy meter sends data to the cloud server via MQTT protocol, where the utility and consumers can monitor data through the HTML page and perform necessary actions. Among the key features of the system include remote connection and disconnection of the meter by admin, setting up of usage limits by the consumer to reduce unnecessary usage, and remote access to load control by the consumer. The 
system, however, is largely focused on postpaid metering systems where consumers bill processing and payments are done at the end of each month. This is contrary to the current trend of smart grid technologies, where prepayment services are the preferred model of business by utility companies.

In [22], the author proposed an IoT based smart energy meter that records energy consumption minutely and sends data to the ThingSpeak cloud server. In addition to power theft detection, both the utility and consumer can view consumption data at the web portal which is updated after every interval. However, the system does not incorporate energy usage feedback mechanisms to enable consumers to be notified during critical events like abnormal electricity usage or unit depletion. In addition to that, the cloud server to which data is uploaded requires extra funds to subscribe for premium data storage space, which is not suitable for the fast-expanding mini-grid companies.

In [23], a GSM-based smart electric metering system has been developed that is capable of reading and sending electricity usage data through GSM modem to the cloud server. The system can send energy usage and bill information to the consumer via SMS, as well as automatically turning OFF the meter upon tampering detection. The consumer notification, however, is notified only when electricity credits are exhausted, which adds little user experience to the consumer energy usage awareness.

In [24] proposed a GSM-based metering system for monitoring and controlling consumer meters. The system uses a GSM modem to relay command and data messages between utility and meter via SMS. Power reading, remote connection, and disconnection are among the features which can be accessed via a normal mobile phone. The system, however, involves minima consumer involvement since the remote accessing of the meter is largely done by the utility company. Furthermore, the authors recommends the addition of a graphical user interface (GUI) feature in addition to the SMS feature to make the system more user-friendly to average users.

In [25], the author proposed a GSM module embedded intelligent electricity metering and billing system to communicate with the utility control centre via SMS. Consumers can access and manage their usage via an embedded Liquid Crystal Display (LCD) or web portal. The meter readings are processed by a bill processing server, which then forwards data to the utility centre database and consumers mobile handset via SMS. The same data is sent back to the meter LCD interface of the meter. The consumer can pay for the bill by purchasing and sending a token to the billing server via SMS, which will authenticate the meter and turns it on. The authors recommend the integration of dual-mode between SMS and online web portal to enable consumers to access their usage history easily.

\section{Material and Methods}

\subsection{According Study Area}

This study was conducted in Ngurdoto Village, Arumeru District in Arusha and Mkalama Village, Hai District in Kilimanjaro, located on the Northern parts of Tanzania. At these villages, a renewable energy company, Innovative Technology and Energy Centre (iTEC), has installed solar mini-grids (each with a 10-kilowatt maximum capacity) whereby more than 4000 villagers are expected to benefit from electricity supplied from the installed solar plants.

\subsection{Population Sampling}

In this study, the target population sample was selected for the purpose of defining system requirements. In order to accomplish this task, a non-probability purposeful sampling method was used to collect information from consumers whose homes were connected to the mini-grids [26]. A total of 106 respondents 
were involved in data, from which 63 were from Mkalama and 43 were from Ngurdoto. Also, a total of 8 technical staff from solar mini-grid companies were interviewed at various times.

\subsection{Data Collection}

This study used a mixed research method to obtain appropriate and relevant information for the development of the proposed system, using both qualitative and quantitative approaches to data collection [27]. The qualitative approach was used to collect the solar mini-grid company's technical requirements regarding the infrastructure needed to incorporate consumers into the monitoring system. The quantitative approach was used to determine the extent of the research problem, the knowledge of consumers, and their perception of energy monitoring systems ' usability.

\subsection{System Development Approach}

This study used the Rapid Application Development (RAD) model to design and develop a web-based, low-cost, two-way electricity usage monitoring system. The approach has been chosen because it requires constant user interaction and iterative design to ensure that only the necessary and important features are implemented into the system within a short timeframe [28].

\subsection{System Requirements}

Information gathered from consumers, utility staff, and other secondary sources were used as key inputs to define the necessary features to be incorporated into the proposed system. System functional and non-functional requirements are presented in Table 1. Such requirements were collected from consumers and utility companies, who are the potential stakeholders of the proposed system.

Table 1. System Requirements

\begin{tabular}{|c|c|}
\hline System Requirement & Description \\
\hline Measured parameters & $\begin{array}{l}\text { The monitoring system should continuously record current, voltage, and compute kilowatt-hour units } \\
\text { from each smart meter. }\end{array}$ \\
\hline $\begin{array}{l}\text { Meters Information } \\
\text { Management }\end{array}$ & $\begin{array}{l}\text { The system administrator should be able to register each meter's information to the database to match } \\
\text { with a corresponding consumer. }\end{array}$ \\
\hline User Account Management & $\begin{array}{l}\text { All consumers must be registered and managed by the system administrator or system staff, providing } \\
\text { each of them with both username and password. }\end{array}$ \\
\hline Data Visualization & $\begin{array}{l}\text { The system should provide data visualization in graphical format. The graph should display consumed } \\
\text { units within a specified time range, with the corresponding total cost. }\end{array}$ \\
\hline Notification & $\begin{array}{l}\text { The system should notify consumers by email/SMS when the remaining units reach a minimum } \\
\text { threshold value. }\end{array}$ \\
\hline Security & $\begin{array}{l}\text { The system should authenticate all system users to ensure the security of monitoring infrastructure and } \\
\text { consumers' privacy. }\end{array}$ \\
\hline Usability & $\begin{array}{l}\text { Users with different computer literacy levels should be able to interact easily with system interfaces. } \\
\text { Only the necessary features should be included. }\end{array}$ \\
\hline
\end{tabular}




\section{Proposed System Architecture}

The block diagram of the system framework is shown in Fig.1. The system incorporates the use of Internet of Things (IoT) to manage each consumer's energy consumption data. To ensure low-cost system design, the mini-grid center uses a Low Power Wide Area Network (LPWAN) technology to securely collect and transmit data from all smart meters via a single GPRS gateway to the cloud server. Another level of security is enforced on the application layer by restricting the execution of all client-server requests to the database by the application server, ensuring the authentication of various parameters such as meter identification, consumer identification, session management, and token management.

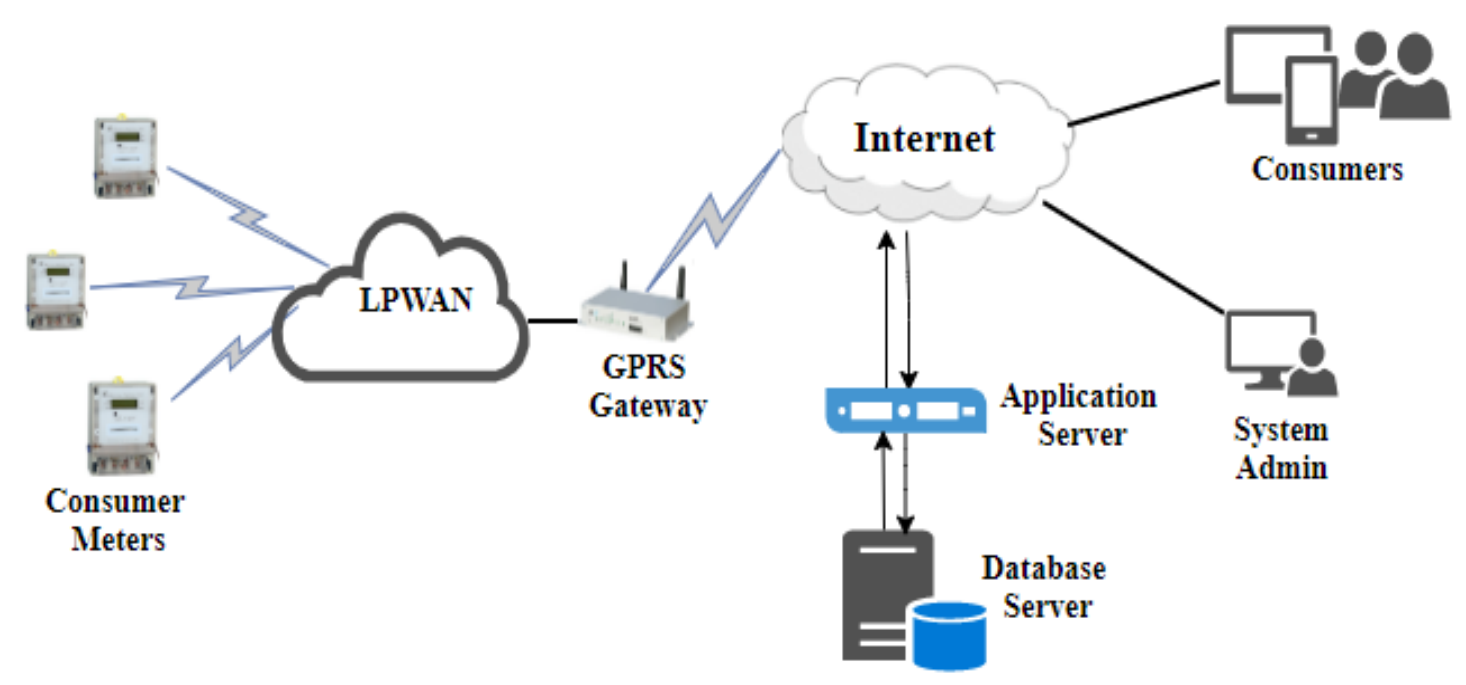

Fig.1. Proposed System Architecture

\subsection{Smart Meter Unit}

A smart meter unit contains a microcontroller system, current and voltage sensors, a relay module, a radio frequency (RF) module, and an LCD. After rigorous assessment of a suitable and low-cost microcontroller, the ATmega2560 microcontroller board was selected as the controller unit because of its low cost and a large number of input/output pins compared to other microcontrollers..

Current and voltage were measured by using the SCT-013-000 non-invasive current sensor and a ZMPT101B voltage transformer, respectively. Such sensors were selected due to their accuracy, are easily available locally, and have a built-in calibration trim potentiometer. The microcontroller was programmed by using $\mathrm{C} / \mathrm{C}++$ libraries. The LCD module is made up of a $20 \mathrm{x} 4$ character LCD screen. The screen size is sufficiently large to handle many variables, such as current, voltage, power, and remaining credits.

\subsection{Data Transmission Unit}

The LPWAN infrastructure was designed by integrating each smart meter system with MKR1310 RF modules that communicate with the local monitoring center using 433/868/915 MHz unlicensed frequency bands. This model minimizes data-related operating costs if each smart meter is designed to communicate 
with the cloud server directly. Mini-grid data is sent over the existing GPRS network to the cloud server through HTTP Request messages. Fig.2. illustrates the flowchart diagram of the data transmission unit.

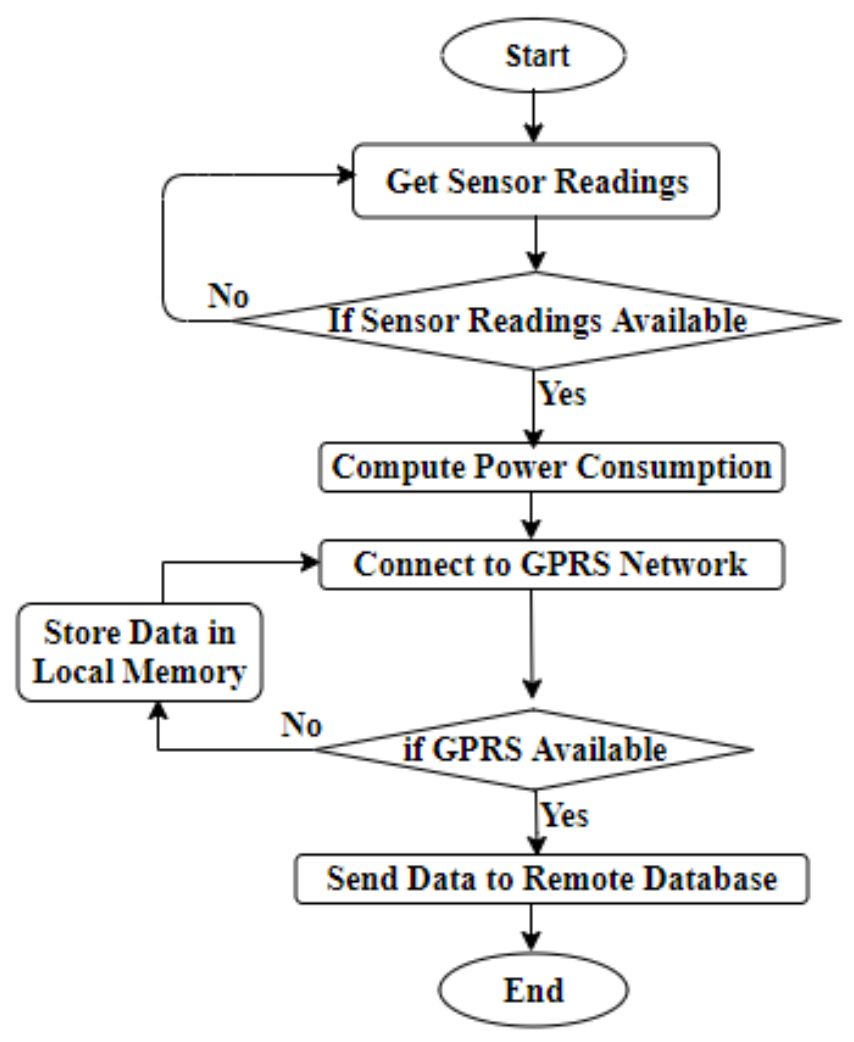

Fig.2. Data Acquisition Unit Flowchart

\subsection{Database Server}

The application database is developed using the MySQL framework, as it is an open-source database management system that is simple to customize, has robust technical support, and runs on many platforms, including Windows, Linux, and others. [29].

\subsection{Web Application}

The web application handles all processes of the application layer system, including user authentication, meter authentication, consumer management, and records of payment transactions. The functionalities on the server side have been developed using Hypertext PreProcessor (PHP). PHP is an open-source scripting language on the server-side with widespread community support and many online libraries available. The client-side interfaces were developed by using Hypertext Markup Language (HTML), Cascade Styling (CSS), and JavaScript language [30]. Xcharts JavaScript library has also been used to model the graphical user interface of the energy usage interface due to its powerful and latest libraries available [31]. Fig.3 shows the Use Case Diagram of the web application's main features and actors. 


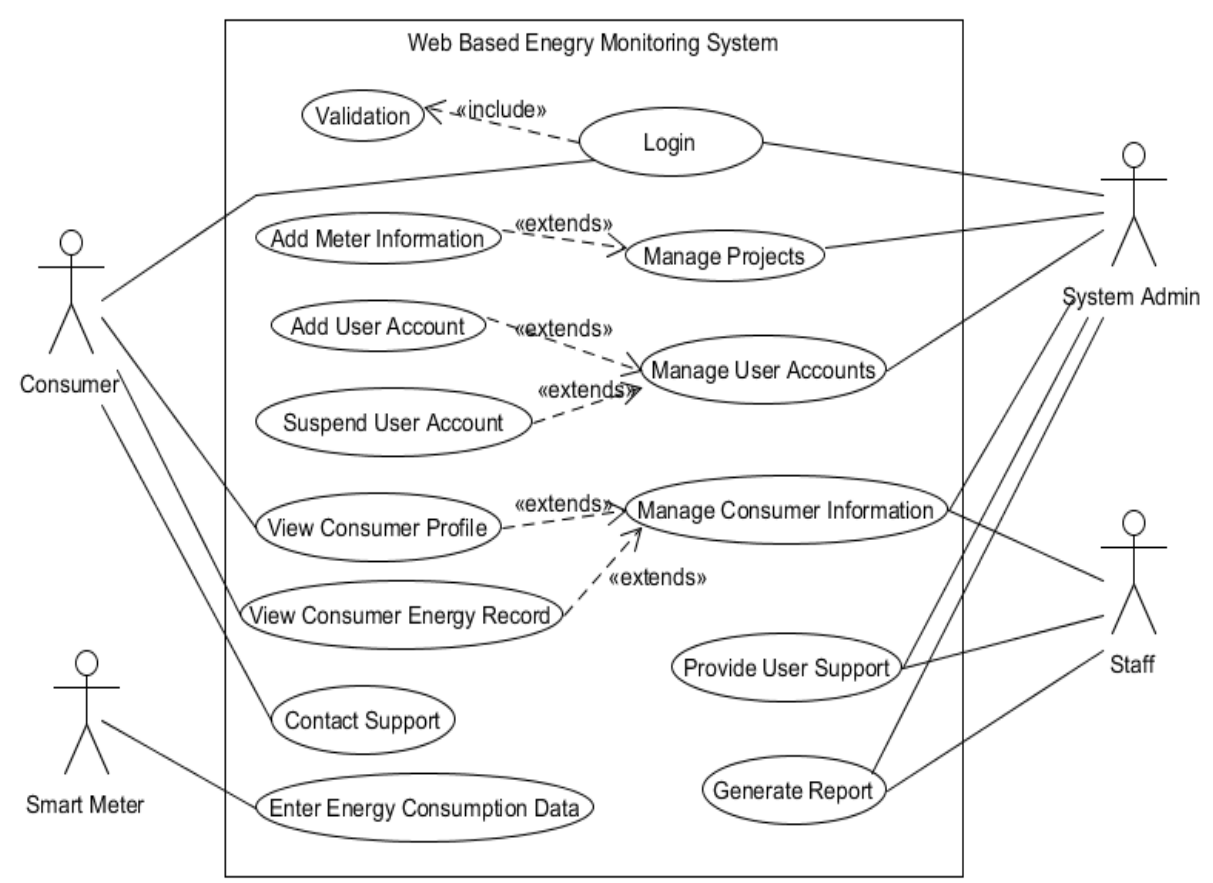

Fig.3. Use Case Diagram of the System's Web Application

\subsection{Payment Unit}

Given the nature of Sub-Saharan Afrcian's use and access to financial services, many people do not have credit or bank accounts. Tanzania, particularly, has access to formal banking services for less than $10 \%$ of the adult population. Consequently, most transactions for utility services are made by mobile money services provided by cellular network service providers. These services have been dominated by Vodacom (M-PESA), Millicom (TIGO-PESA), Airtel (Airtel Money), Hatolel (Halo-Pesa) and TTCL (T-PESA) [32]. Mobile payment systems usually use reference numbers to validate a two-party payment transaction. In this study, a virtual payment environment based on the reference numbers was developed by using the Vodacom M-PESA menu as a case study to incorporate a mobile payment interface

\subsection{Notification Unit}

The SMS and email alert system has been incorporated into the web application to improve consumer awareness of the use of electricity when they upload credits and when the remaining credits a lower than a predefined minimum threshold. This feature is particularly useful for prepaid schemes, whereby consumers need to be aware of crucial consumption circumstances so that they can plan for credits top-up. Due to its ease of integration with web application frameworks compared to other SMS APIs, a cloud-based SMS API was introduced using nexmo-API [33]. Fig.4 shows the notification unit's flowchart diagram. 


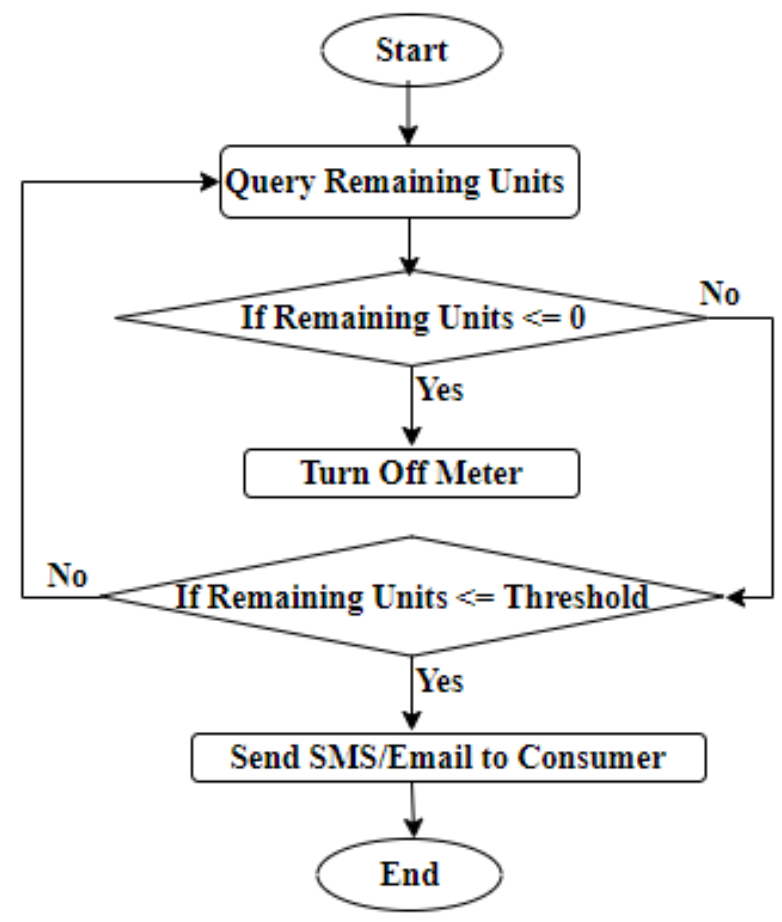

Fig.4. Notification Unit Flowchart Diagram

\section{Results and Discussion}

\subsection{System Testing Methodology}

After system development, both white-box and black-box methods were used to test and validate the system [34]. First, each system unit was tested to determine its performance and comply with system requirements. Finally, integration testing was performed to determine the overall usability and reliability of the system. The results obtained during the testing process are discussed in the following sections.

\subsection{Smart Meter Unit}

The low-cost smart meter prototype was designed, developed, and enclosed within a plastic case for portability purposes. Be default; the LCD screen shows the operating current, voltage, and total power consumed by the load connected from the meter. Fig.5 shows the completed smart meter prototype during testing while Fig. 6 shows the smart meter unit enclosed in a water proofing box. 


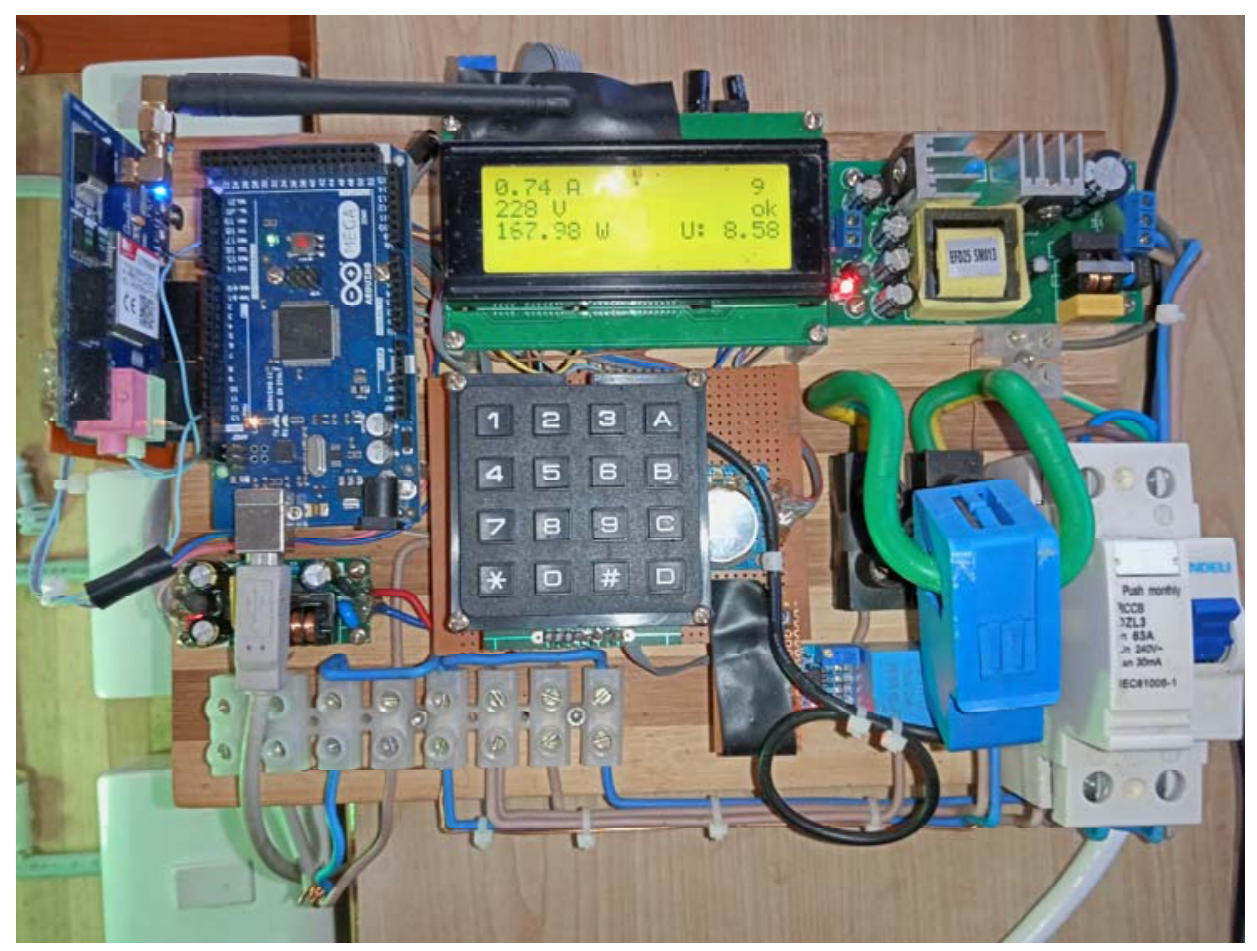

Fig.5. Smart Meter Unit During Testing

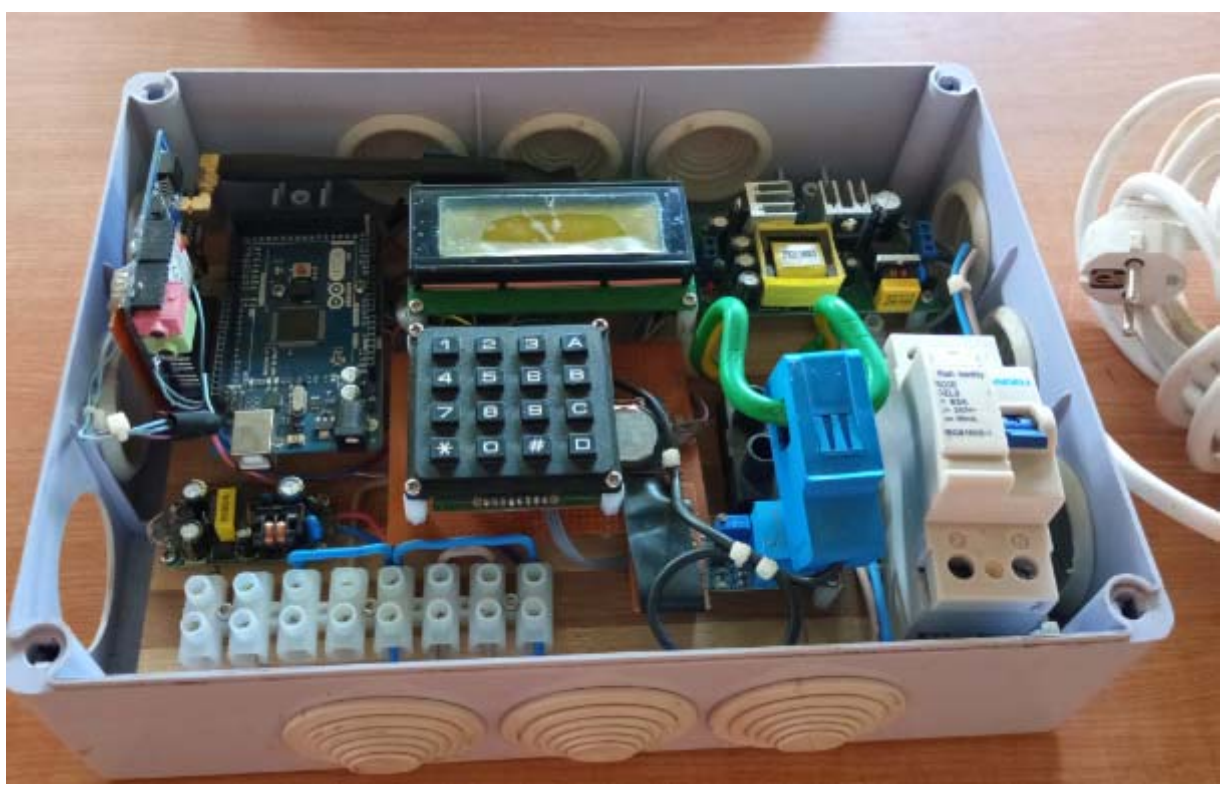

Fig.6. Smart Meter Unit Enclosed Inside a Water Proofing Box 


\subsection{Data Transmission Unit}

Consumption data from the smart meter units is collected at the local monitoring centre as shown in Fig.7(a), via LPWAN, which communicates with the cloud server via the GPRS gatetway shown in Fig.7(b). To ensure reliable data communication between smart meter units and local monitoring centre, several RF base stations have been installed across the mini-grid network, as shown in Fig.8.

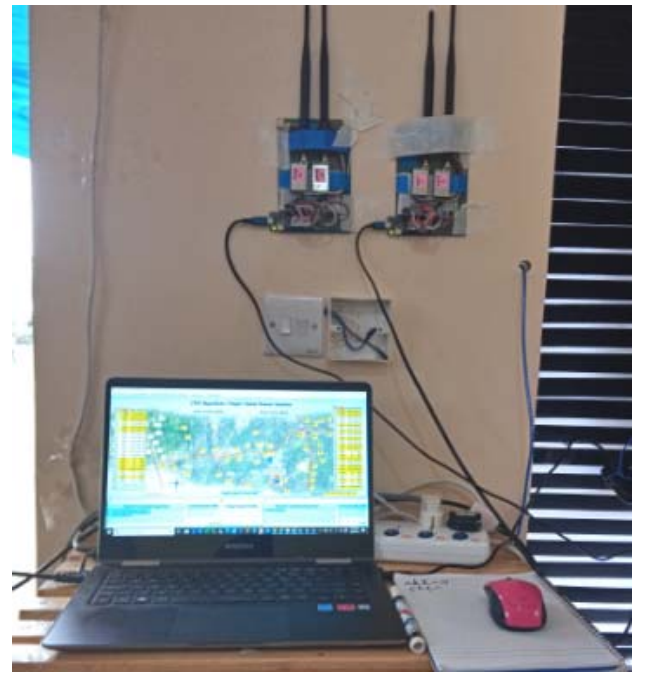

(a)

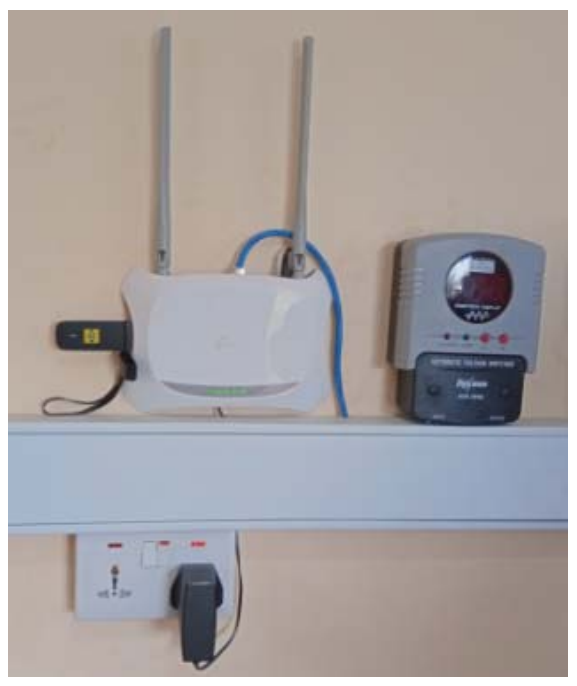

(b)

Fig.7. (a) Local Monitoring Centre (b) GPRS Gateway

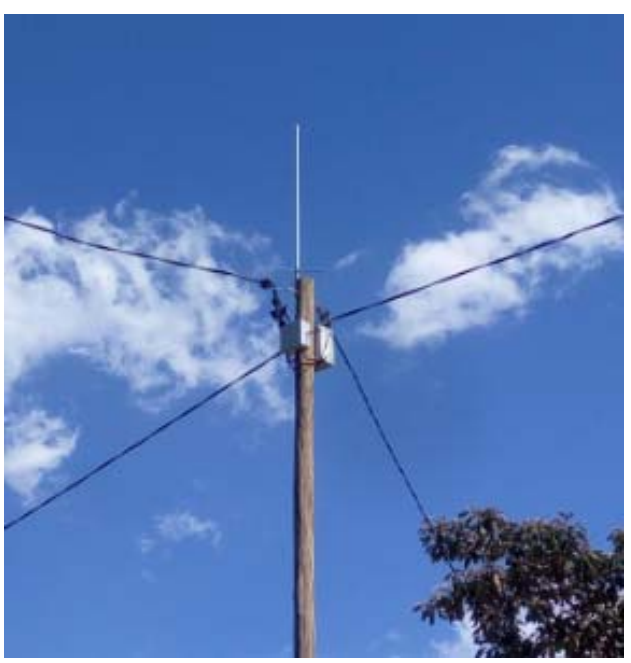

Fig.8. LPWAN Base Station For Enhancing Data Collection 


\subsection{Grids Information Dashboard}

This interface is only visible to the system administrator of the utility company. As shown in Fig.9, when the administrator logs into the system successfully, they can view total energy consumption per grid per month. This information is useful for evaluating grid production capacity versus demand for current and future planning purposes.

The following interpretation can be deduced from the grid information dashboard:

- The overall power usage trend for both mini-grids is increasing because as time goes by, more customers are connected to the system.

- Although both mini-grids have the same power capacity, Ngurdoto's consumption data is relatively higher than Mkalama because of the difference in the number of connected consumers and the nature of economic status of each region. Many consumers in Mkalama use electricity mainly for lighting and charging, while in addition to lighting and charging, Ngurdoto villagers use electricity for other uses.

The overall decrease in power consumption during May and June was due to the upgrade of monitoring systems in both mini-grids, which resulted in intermittent availability of power during this time.
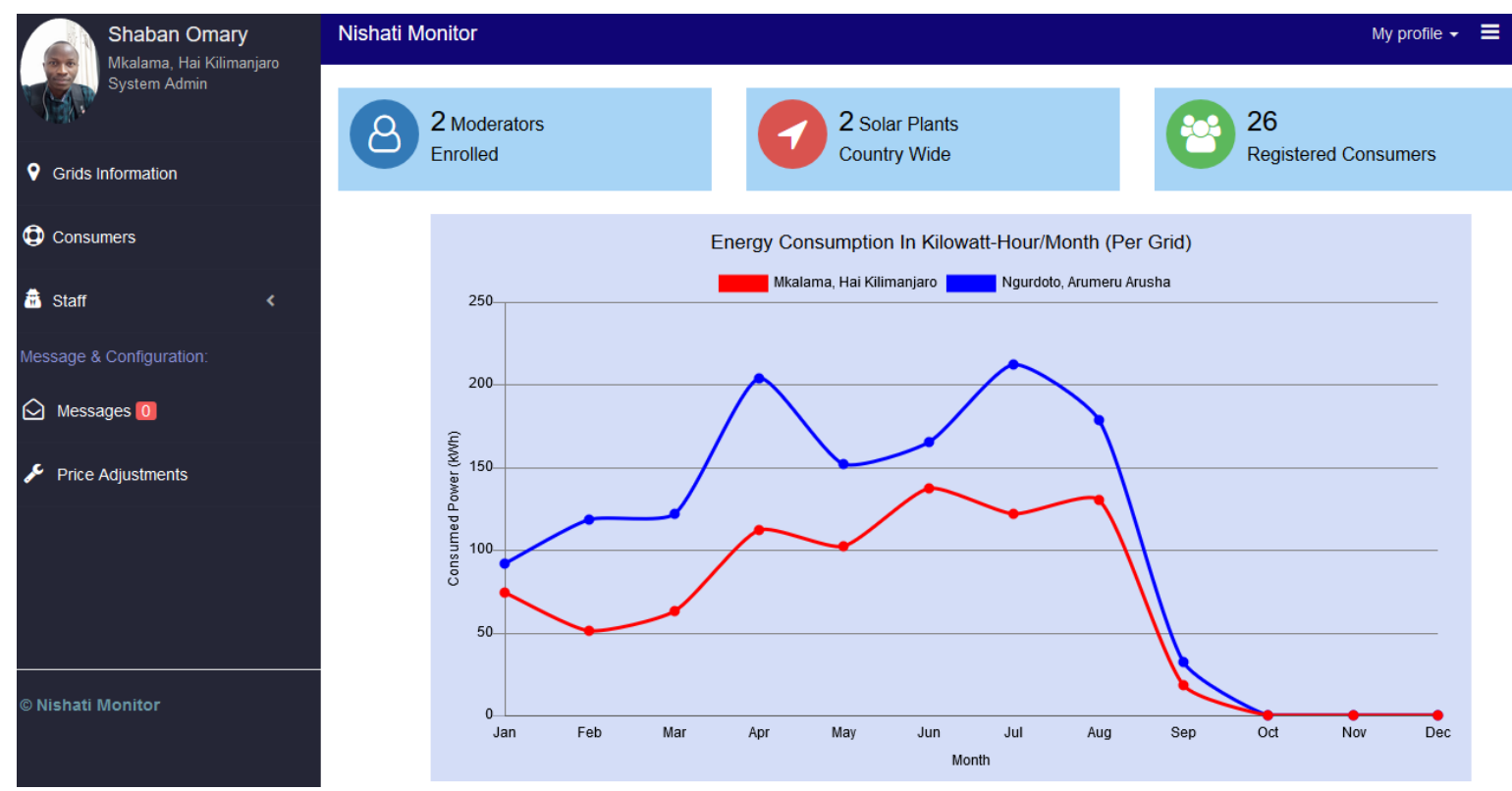

Fig.9. Grids Information Dashboard

\subsection{Consumer Management}

This interface is also visible to the system administrator only. The administrator must register all consumer and meter information. As shown in Fig.10, the administrator may add, suspend, and modify consumer information via the consumer management page. In addition to consumer management, the general information on the connection status of consumers and usage can also be viewed at the bottom of the page, providing a quick picture of the mini-grids operating status. 


\section{Registered Consumers}

\begin{tabular}{|c|c|c|c|c|c|c|}
\hline \multicolumn{6}{|c|}{ Type by name or meter no $\ldots$} & \multirow[t]{2}{*}{ + New Consumet } \\
\hline Consumer No: & Name & Location & Connection Status & Actions & & \\
\hline 13 & Daniel Maranga & Ngurdoto, Arumeru Arusha & $\square$ & E & G Edt & $\mathbf{x}$ Suspend \\
\hline 14 & Kato Mathias iganiza & Ngurdoto, Arumeru Arusha & $\square$ & E E View & C Edt & X Suspend \\
\hline 15 & Damian Lewis Makame & Ngurdoto, Arumeru Arusha & $\square$ & 틀 view & C Edt & X Suspend \\
\hline 16 & Salimin Amour Majuto & Ngurdoto, Arumeru Arusha & 口 & 툐 View & G Eot & X Suspend \\
\hline 17 & Sabina Aidan Zakayo & Ngurdoto, Arumeru Arusha & $\square$ & E & C Edt & $\boldsymbol{X}$ Suspend \\
\hline
\end{tabular}
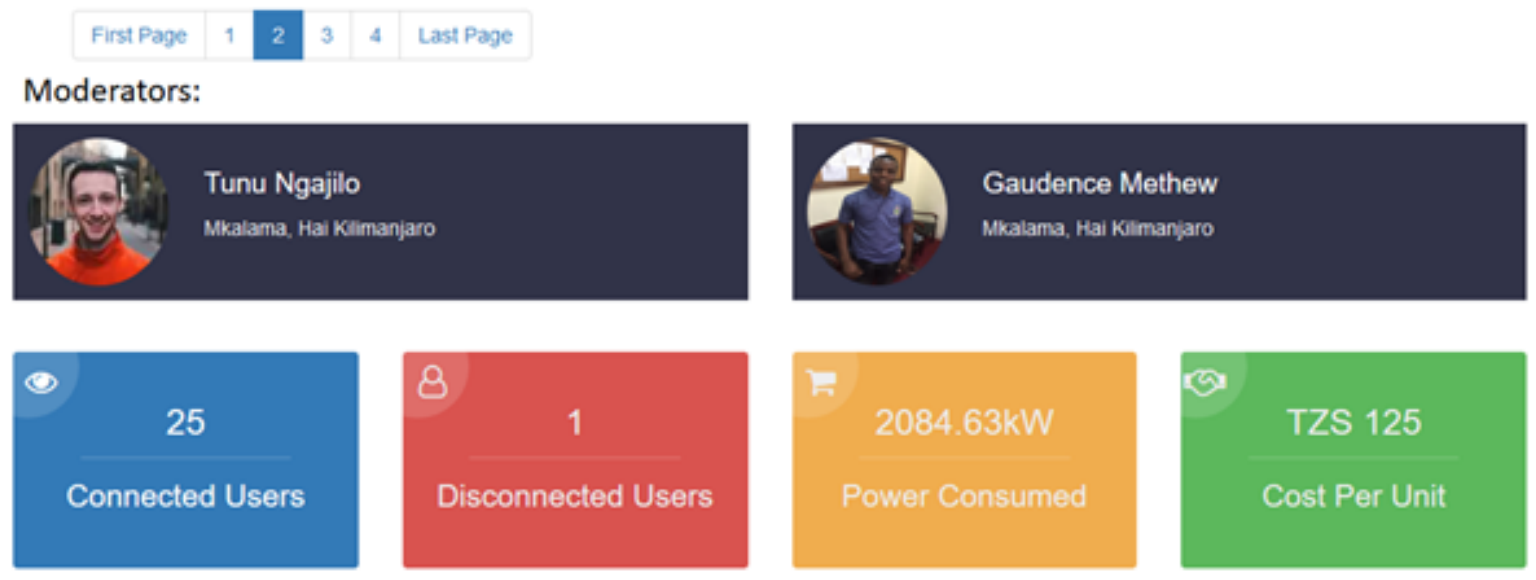

Fig.10. Consumer Management Interface

\subsection{Electricity Consumption Data Visualization}

When the consumer logs into the web portal successfully, they are directed their profile where they can also view the remaining credits, as shown in Fig.11(a). Also, both the consumer and the administrator can view energy usage history presented in a user-friendly graphical format, as shown in Fig.11(b). By default, the graph shows the past seven days' energy usage history. The interface also shows total consumption units and associated costs for the specified timeframe. By providing this information, consumers can make informed budget decisions to allow them to adapt their actions in the use of energy to their economic status. 


\section{Nishati Monitor}

Consumer No: 00010

Account Type: Prepaid

\begin{tabular}{|l|l|}
\hline User information & \\
\hline Consumer Name: & Erick Samson \\
\hline Consumer Email: & ericksamjf@gmail.com \\
\hline Consumer Phone: & 0715565852 \\
\hline Remaining Units: & 12.5 \\
\hline Connetion Status: & ON \\
\hline \$ & \\
\hline
\end{tabular}

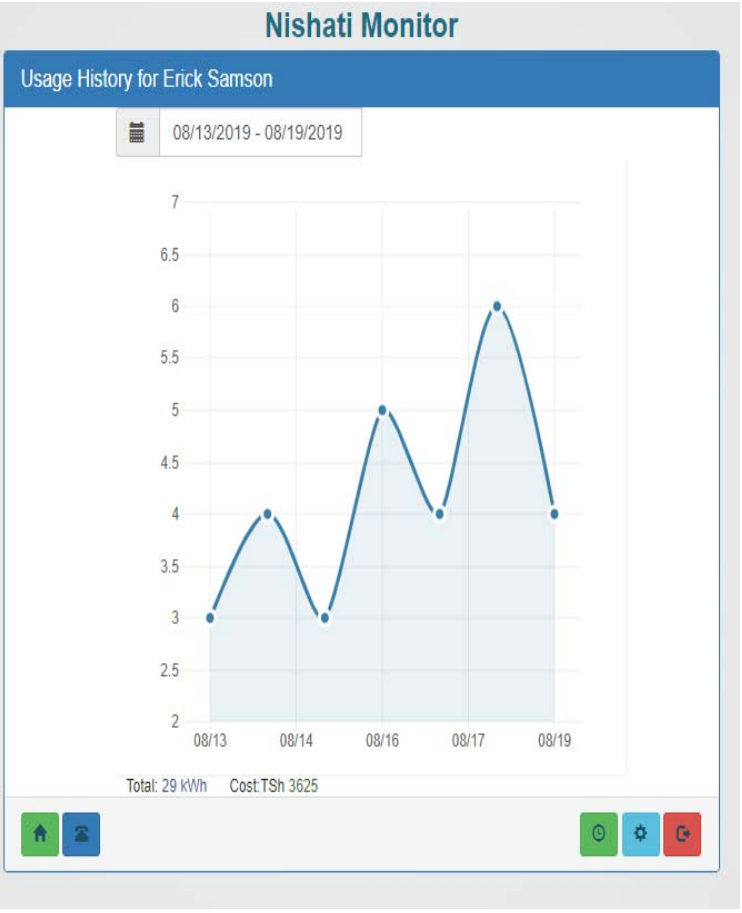

Fig.11. (a) Consumer Profile (b) Energy Consumption History

\subsection{Payment Unit}

When a consumer intends to make a bill payment, they are redirected to the payment menu, with predefined amounts, as shown in Fig.12(a). After selecting the payment amount, the mobile payment menu will appear with payment instructions depending on the amount the user selects, as shown in Fig. 12(b). When the user submits a payment reference number, the system will compare the submitted input to the value received from the SMS gateway before updating remaining units of electricity to the consumer's meter account. 
Nishati Monitor

Online Payment System

Select the amount you need to pay

\begin{tabular}{|c|c|c|}
\hline \multicolumn{2}{|l|}{1000 TZS } & Buy \\
\hline 2000 TZS & & Buy \\
\hline 5000 TZS & & Buy \\
\hline $10000 \mathrm{TZS}$ & & Buy \\
\hline त 2 & (c) & anl \\
\hline
\end{tabular}

\section{Nishati Monitor}

\section{Online Payment System}

Follow the Procedure Below for Payment

- Dial * $150 * 00$ \# to get the M-Pesa menu

- Select Pay By M-Pesa

- Choose business number 261144

- Enter your reference number as AL125897V as the Account Number

- Enter your Amount (TZS. 5000)

- Enter PIN

- Confirm Payment

- You will receive a Payment notification from M-Pesa

- Copy and Submit the Reference Number in the Box Below

Enter Reference Number $\quad$ Submit

a

Fig.12. (a) Bill Payment Interface (b) Bill Payment Instructions

\subsection{Notification Unit}

Fig.13 shows the SMS message sent to the customer when the remaining units are below the predefined limit for the meter account of the customer. The algorithm behind this feature is to enhance user experience in electricity usage so that customers can make payment arrangements in advance before being disconnected from the service. The minimum threshold value of most households in the study area was estimated from the average daily electricity usage data collected from consumers.

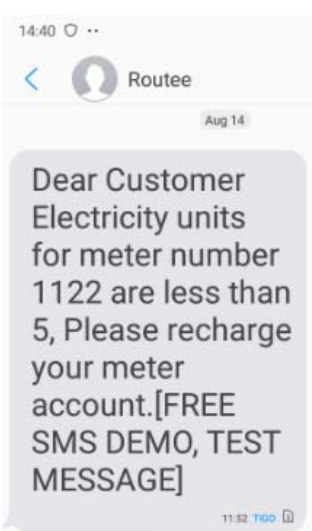

Fig.13. Usage Notification Message 


\section{Conclusion}

The web-based two-way electricity usage monitoring system for remote solar mini-grids has been proposed, developed, and tested. The system tracks electricity consumption and sends data to the cloud server after every one minute under the current configuration. This data can be used for various purposes, including the power consumption behaviour of users, evaluating the demand for future energy requirements, and identifying abnormal usage of electricity. The developed web portal allows both company system administrators and consumers to have convenient and safe access to information about the utilization of power. Also, SMS/email notification has been incorporated into the system to enhance consumers' awareness of electricity usage, especially in critical events such as when a consumer's meter account is about to run out of credits.

Also, a virtual mobile payment system has been integrated into the web portal, which uses transaction reference numbers for verifying bill payments. Results show that the developed system could improve accessibility to energy consumption information to both utility companies and consumers. Access to such data would increase awareness towards the economical utilization of electricity, which is an important aspect of the resource-constraint solar mini-grids infrastructure. Compared to the existing meters in the national grid, which cost more than 130 U.S. dollars for a single customer, the complete system costs an average of 70 U.S. dollars, making it suitable for remote solar mini-grid companies due to their limited financial resources.

In addition to the business application, this study also adds contribution to the existing literature by introducing a new cost-effective method of monitoring domestic electricity usage by utilizing the existing technologies. Other researchers could expand this research by focusing on several specific issues of the electricity usage monitoring system, such as improving end-to-end consumer data security issues across the GPRS network and research on distributed data management, particularly for the mini-grid companies with a large number of consumers.

\section{References}

[1] International Energy Agency. Global Energy \& CO2 Status Report: The latest trends in energy and emissions in 2018. 2018;21-2.

[2] National Bureau of Statistics. Energy Access Situation Report, 2016. Tanzania Mainland. 2016. 40-42 p.

[3] Chaplin D, Mamun A, Protik A, Schurrer J, Vohra D, Bos K, et al. Grid Electricity Expansion in Tanzania: Findings from a Rigorous Impact Evaluation. Mathematica. 2017;(March):11-2.

[4] Mandelli S, Barbieri J, Mereu R, Colombo E. Off-grid systems for rural electrification in developing countries: Definitions, classification and a comprehensive literature review. Renew Sustain Energy Rev. 2016;58:1621-46.

[5] Ahlborg H, Hammar L. Drivers and barriers to rural electrification in Tanzania and Mozambique - grid extension, off-grid and renewable energy sources. 2011.

[6] International Bank for Reconstruction and Development. State of Electricity Access Report 2017 [Internet]. 2017. 51 p. Available from: http://elibrary.worldbank.org/doi/book/10.1596/26646

[7] Odarno L, Sawe E, Swai M, Katyega MJJ, Lee A. ACCELERATING MINI- GRID DEPLOYMENT IN SUB-SAHARAN AFRICA. :6-7.

[8] Hartvigsson E, Ehnberg J, Ahlgren E, Molander S. Assessment of load profiles in minigrids: A case in Tanzania. Proc Univ Power Eng Conf. 2015;15:1-5.

[9] Vine D, Buys L, Morris P. The Effectiveness of Energy Feedback for Conservation and Peak Demand: A Literature Review. Open J Energy Effic. 2013;02(01):7-15. 
[10] Kovacs D, Kovatsch M. Communication Technologies for Smart Objects. 2014;1-8.

[11] Alahakoon D, Yu X. Smart Electricity Meter Data Intelligence for Future Energy Systems: A Survey. IEEE Trans Ind Informatics. 2016;12(1):425-36.

[12] Palaniappan S, Asokan R, Bharathwaj S, N S. Automated Meter Reading System - A Study. Int J Comput Appl. 2015;116(18):39-46.

[13] Garcia FD, Marafão FP, Angelino De Souza W, Pereira Da Silva C. Power Metering: History and Future Trends. $2017 \quad$ [cited 2018 Oct 26];29-30. Available from: https://www.computer.org/csdl/proceedings/greentech/2017/4535/00/07923934.pdf

[14] Alahakoon D, Yu X. Advanced analytics for harnessing the power of smart meter big data. Proc - 2013 IEEE Int Work Intell Energy Syst IWIES 2013 [Internet]. 2013;40-5. Available from: https://ieeexplore.ieee.org/abstract/document/6698559

[15] TCRA. January-March 2019 Operators ' Submissions [Internet]. 2019. Available from: https://www.tcra.go.tz/images/headlines/TelCom_Statistics_March_2019.pdf

[16] Marie-Claire F, Dominique H-M. Mobile Web Applications. Pro HTML5 with Vis Stud 2015. 2015;139-65.

[17] Ashna, K.; Sudhish G. GSM Based Automatic Energy Meter System with Instant Billing. Int J Adv Res Electr Electron Instrum Energy. 2013;65-72.

[18] Singh D, Jain P. IoT BASED SMART. 2016;5(7):2080-4.

[19] Joshi DSA, Kolvekar S, Raj YR, Singh SS. IoT Based Smart Energy Meter. Bonfring Int J Res Commun Eng. 2017;6(Special Issue):89-91.

[20] Jain S, Pradish M, Paventhan A, Saravanan M. ISGW 2017: Compendium of Technical Papers [Internet]. Vol. 487. Springer Singapore; 2018. 19-28 p. Available from: http://link.springer.com/10.1007/978-981-10-8249-8

[21] Pandit Miss SnehaMandhre Miss MeghanaNichal S. Smart Energy Meter using internet of Things (IoT). VJER-Vishwakarma J Eng Res [Internet]. 2017;1(2):222-9. Available from: http://www.vjer.in/vollissue2/vjer010228.pdf

[22] Barman BK, Yadav SN, Kumar S, Gope S. Energy Utilization in Smart Grid. 2018 2nd Int Conf Power, Energy Environ Towar Smart Technol. 2018;2-4.

[23] Hassan Mir S, Ashruf S, Bhat Y, Beigh N. Review on Smart Electric Metering System Based on GSM/IOT. Asian J Electr Sci [Internet]. 2019;8(1):1-6. Available from: www.trp.org.in

[24] Ugonna EE, Ademola AK, Olusegun AT. Design and construction of a smart electric metering system for smart grid applications: Nigeria as a case study. 2018;(July):800-4.

[25] Matthews VO, Adekitan AI, Idiake US, Noma- E. Wireless Intelligent Electricity Metering and Billing System ( WIMBIS ) Abstract : 2018;4(4):57-61.

[26] Etikan I, Musa SA, Alkassim RS. Comparison of Convenience Sampling and Purposive Sampling. 2016;5(1):1-4.

[27] Lewis S. Qualitative Inquiry and Research Design: Choosing Among Five Approaches. Health Promot Pract. 2015;16(4):473-5.

[28] Voigt BJ. J. Dynamic System Development Method. Technology [Internet]. 2004;(January):18. Available from: https://files.ifi.uzh.ch/rerg/arvo/courses/seminar_ws03/14_Voigt_DSMD_Ausarbeitung.pdf

[29] Yu X, Yi C. Design and implementation of the website based on PHP \& MYSQL. 2010 Int Conf E-Product E-Service E-Entertainment, ICEEE2010. 2010; 
[30] Nixon R. PHP, MySQL,JavaScript \& CSS. 2012. 582 p.

[31] Almeida F. Creation of Charts with PHP, HTML5 and Javascript. 2017;(January 2016).

[32] Tanzania Invest. Tanzania Mobile Money Market [Internet]. 2019. 2019 [cited 2019 Sep 4]. Available from: https://www.tanzaniainvest.com/mobile-money

[33] Nexmo API Platform. SMS API For Your Business | Nexmo The Vonage API Platform [Internet]. 2017. 2018 [cited 2019 Sep 4]. Available from: https://www.nexmo.com/products/sms

[34] Sawant AA, Bari PH, Chawan P. Software Testing Techniques and Strategies. J Eng Res Appl. 2012;2(3):980-6.

\section{Authors' Profiles}

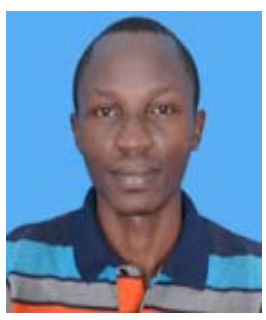

Shaban Omary is a Tutorial Assistant in the Department of Electrical Engineering, University of Dar es Salaam. He completed his Bachelor's degree in Telecommunication Engineering in 2015 at the University of Dar es Salaam. Currently, he is pursuing a Master's degree in Information and Communication Science and Engineering at the Nelson African Institution of Science and Technology, Tanzania.

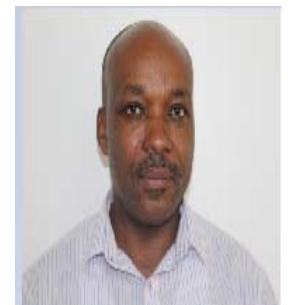

Anael E. Sam is a senior lecturer at the School of Computation Communication Science and Engineering (CoCSE) at NM-AIST. He earned his Ph.D. in Electronics Engineering from the Faculty of Electrical Engineering and Information Technology (FEI) at Slovak University of Technology (STU), Slovak Republic. Previously he held the position of Senior System Engineer for Nokia Siemens Networks R\&D department (2010- 2012). $\mathrm{He}$ also worked as Senior System Engineer in R\&D of Logica Slovakia s.r.o. a subsidiary of Logica Plc. (2007-2010). He worked for Siemens Program and System Engineering (PSE) s.r.o. Slovakia (2004 - 2007). Also he worked as Software Expert for Alcatel Lucent, Slovakia (2000-2003), involved with the Alcatel S1200 firmware development and quality assurance. At his current position, he led a team of Information Communication Experts who bid to host the Centre of Excellency for ICT in East Africa (CENIT@EA). He is currently the CENIT@EA Overall Technical and Scientific Coordinator. The CENIT@EA is mandated to run the Embedded and Mobile System (EMoS) Master's degree programme.His research interests are: Cyber Security, Radio, multimedia and mobile Communication Systems; Electronics and Telecommunication Engineering, Software Quality Assurance Engineering; Mobile Networks Planning and Optimization. He authored and co-authored more than 35 scientific journal papers and more than 10 papers presented in scientific conferences.Dr. Anael Sam is a practitioner and holder of ISQTB Foundation Level Certificate of International Software Testing Qualifications Board).

How to cite this paper: Shaban Omary, Anael Sam. "Web-Based Two-Way Electricity Monitoring System for Remote Solar Mini-Grids", International Journal of Engineering and Manufacturing(IJEM), Vol.9, No.6, pp.24-41, 2019. DOI: 10.5815/ijem.2019.06.03 